\title{
¿Es posible una ética común en urologia?
}

\author{
Jara Rascón J. \\ Coordinador de la Oficina de Ética de la AEU \\ Hospital General Universitario Gregorio Marañón. Madrid
}

Actas Urol Esp. 2006;30(10):969-973

$\mathrm{L}$ a introducción de la ética como una disciplina de creciente interés en el currículum académico de las Facultades de Medicina, así como la aparición en el medio hospitalario de los Comités de ética asistencial y los dedicados a velar por la ética de los ensayos clínicos, ha dado lugar a que las intuiciones personales para justificar la propia actuación en el terreno de la ética profesional hayan quedado ya desfasadas. Evidentemente, la ausencia de normas éticas conjuntas ha sido durante demasiado tiempo una excelente válvula de escape para "justificar" situaciones de privilegio por parte de algunos que, en base a un malentendido paternalismo, encontraban en esta situación de vacío, tanto moral como legal, la atmósfera perfecta para evadir responsabilidades. En un primer intento de evitar en la medida de lo posible estas situaciones, surgieron los Códigos Deontológicos propiciados en nuestro país por la Organización Médica Colegial, intentando transmitir una exigencia de buena praxis a los profesionales del ámbito de la salud y servir tanto de orientación como de defensa ante situaciones de conflicto entre los médicos y la sociedad.

Sin embargo, la progresiva toma de conciencia de los derechos de los pacientes ha llevado a que la sociedad no considere este tipo de mecanismo de autocontrol como suficiente garantía para recibir una adecuada asistencia sanitaria. Por ello, en los últimos años se ha ido creando un cuerpo de doctrina jurídica específica para los cuidados de la salud que comenzó con la Ley General de Sanidad de 1986 y cuyo último paso decisivo se puede considerar la reciente Ley básica reguladora de la autonomía del paciente y de derechos y obligaciones en materia de información y documentación clinica (41/2002, de 14 de noviembre).
Sin duda, se podría considerar que estos avances en materia de obligaciones de los médicos para con sus pacientes, expresados ya incluso en términos legales, suponen un gran salto de calidad en la relación médico-paciente. Pero, ¿es sentido esto así por todos, o al menos por la mayoría, del colectivo médico?. Es relativamente frecuente oír en conversaciones entre nuestros colegas quejas por la falta de tiempo para rellenar los documentos de consentimiento informado, objeciones a la obligación de mantener la confidencialidad o abiertas protestas respecto a las exigencias de los pacientes de recibir un mejor trato. Inversamente, si alguien cercano a nuestros intereses se encuentra enfermo, habitualmente comprendemos de modo pleno su deseo de información, su angustia respecto a un incierto pronóstico o sus exigencias de que se mantenga el secreto profesional. Esto nos conduce a una necesaria reflexión: ¿Son suficientes las medidas legislativas para crear un mejor clima de relación entre los médicos y sus pacientes?. Posiblemente la respuesta mayoritaria a esta pregunta sea que no, y aquí es donde entraría en juego la ética.

La Justicia, con la promulgación de sanciones legales, promueve lo que se ha dado en llamar una "ética de mínimos". Es decir, la conciencia de que se deben cumplir unos mínimos criterios morales en las relaciones humanas porque su incumplimiento daría lugar a una sanción con el objeto de mantener el orden social. En cambio, la ética intenta promover actitudes de excelencia moral, una llamada "ética de máximos", favoreciendo una toma de conciencia de que lo mejor es tratar a los demás como a cada uno le gustaría ser tratado, sin disociar esta regla de comportamiento del respeto a la subjetividad ajena y a los condicionantes de cada situación psicológica individual. Para lograr este ambicioso objetivo, la 
reflexión ética en el campo de la biomedicina, también denominada "bioética", busca sus anclajes más profundos tanto en datos de experimentación (pronósticos más frecuentes, eficacia esperada de actuaciones diagnósticas o terapéuticas,...) como en la reflexión sobre la moralidad o inmoralidad de las actuaciones del ser humano. Profundizando en este tipo de reflexión aplicada a las ciencias de la salud, se ha ido creando un campo específico de argumentación que arranca con el informe Belmont sobre la ética de la investigación en humanos, propiciado por el gobierno de los Estados Unidos en 1978 y que se ha ido explicitando en multitud de textos como el reciente Manual de Ética Médica de la Asociación Médica Mundial y diversos informes elaborados por organismos competentes (Organización Mundial de la Salud, UNESCO, Consejo de Europa,...).

La bioética en España se ha desarrollado, por lo general, en los últimos años a partir del principialismo norteamericano (respeto a los principios de beneficencia, no maleficencia, justicia y autonomía como pilares básicos de comportamiento ético) y en el marco de una ética de mínimos. Sin embargo, en múltiples situaciones de conflicto entre los deseos del paciente y las convicciones del médico, este tipo de deliberación se ha demostrado como insuficiente. Debido a esto, E. Pellegrino ${ }^{1}$ defiende la incorporación del estudio de la Filosofía Moral en la formación obligada de todo el personal sanitario, lo que permitiría conocer más datos de reflexión que permitan responder a las cuestiones de fondo sobre el sentido del sufrimiento, la enfermedad, la búsqueda de curación o los límites de la investigación y la experimentación sobre el ser humano.

Dentro de este nuevo marco ético y legal, la Urologia comparte unas exigencias éticas básicas al común ejercicio de la Medicina: deber de competencia profesional, veracidad en la información suministrada a los pacientes, adecuada gestión de recursos, respeto al final de la vida, control de un desmedido afán de lucro con perjuicio de la salud de los enfermos, etc. Pero también tiene un campo de actuación con específicos debates de marco bioético $^{2}$ que, probablemente, irán aumentando con la progresiva incorporación de nuevas tecnologías a nuestro quehacer profesional, implicando esto, nuevas dudas sobre qué es lo más correcto y dónde está la frontera entre el beneficio que queremos proporcionar a nuestros pacientes y los riesgos o los efectos secundarios que se derivarán de nuestras actuaciones.

\section{El Código de ética de la AUA}

Por ello, la Asociación Americana de Urología (AUA), ya en 1999, presentó un Código de ética propio $^{3}$ que bien podría servir de modelo para otras asociaciones incorporando nuevos aspectos más sensibles o específicos de cada área. En este Código de conducta, quizás menos conocido de lo que debiera, se asumen compromisos indispensables para un correcto ejercicio de la profesión, sustituyendo el antiguo Juramento Hipocrático, por un nuevo pacto entre médico y enfermo más acorde con lo que la sociedad parece reclamar. En concreto, se afirma "Me comprometo a realizar la práctica de la urología con honestidad y colocar el bien y los derechos de mis pacientes por encima de todo lo demás. Me comprometo a tratar a cada paciente como yo desearía que me trataran a mí mismo. Prestaré mis servicios a la humanidad con entero respeto a la dignidad humana, colmando toda medida de servicio y dedicación, adaptando mi habilidad a lo mejor de mis capacidades".

Después de esta genérica exposición de buenas intenciones, se pormenoriza en qué consiste ese servicio y dedicación a los pacientes explicitando la obligación de mantener una formación continuada, la disponibilidad para compartir conocimientos y habilidades con otros colegas de la especialidad y la apertura mental al diálogo y a la búsqueda de consejo cuando se tengan dudas sobre las propias decisiones. Si bien estas facetas de nuestro trabajo habitual no parecen excesivamente difíciles de asumir, el código elaborado por la AUA va mucho más allá en cuanto a exigencias éticas y rompe una lanza contra un indeseable corporativismo al proponer "salvaguardar la profesión de médicos inaceptables en su moralidad o su competencia profesional exponiendo a la autoridad correspondiente la conducta claramente ilegal o inmoral de los miembros de esta profesión, o de aquellos comprometidos en situaciones de fraude o engaño". Evidentemente, no es esperable que estas situaciones sean frecuentes en 
ámbitos de trabajo en equipo, pero no se puede ser tan utópico como para pensar que estos casos planteados sean inexistentes, por lo que la llamada a la responsabilidad y a no colaborar en situaciones de mala praxis con previsibles daños a los pacientes, no debiera parecernos fuera de lugar.

En un contexto más positivo, se mencionan la propuesta de animar a los compañeros con limitaciones en su práctica médica a buscar ayuda y el deber de mantener el secreto profesional dentro de los limites marcados por la legislación. Asimismo, esta propuesta ética, que no se circunscribe al ejercicio de la profesión en el ámbito de la sanidad pública, recuerda la obligación de que las informaciones sobre nuestros logros profesionales sean siempre veraces, lo cual posee en nuestro país incluso un marco legal, recogido en el Real Decreto 1907/1996 que regula la publicidad y promoción de productos, actividades o servicios con pretendida finalidad sanitaria sancionando la publicidad engañosa. En este mismo sentido el Código de la AUA incluye: "Cualquier publicidad que yo haga será honesta y veraz, no falsa, equívoca, fraudulenta, escandalosa o parcial. Mis comunicaciones con el público serán correctas, y no falsearé mi experiencia, mis méritos profesionales o mi capacidad".

¿Es posible abordar el tema de las relaciones con la industria farmacéutica de un modo abierto y sin que esto signifique una intolerable intromisión en el ámbito privado de cada cual?. Desde luego el Código de ética de la AUA incluye este tema entre sus postulados ya que, si existe una conciencia limpia de que este tipo de relaciones se están realizando honestamente, parece mejor clarificar situaciones equívocas. Cuando se acepta la idea de que este es un tema "tabú" sin duda se está propiciando el convencimiento de que existe algo que ocultar, un sentimiento de mala conciencia colectivo que puede trascender a la opinión pública dañando nuestra imagen profesional. Por ello, no debería parecernos extraño que este tema se aborde con claridad en foros adecuados, evitando sombras de sospecha y clarificando situaciones ante los organismos competentes. Con respecto a esto, una exigencia repetidamente planteada es la necesidad de posibilitar una formación continuada subvencionada.
También el consentimiento informado, sin dotación de tiempo adicional en las consultas para desarrollarlo adecuadamente, ha sido objeto de numerosas críticas. Sin embargo, cada vez está más claro que debe ser considerado parte integral de la atención médica prestada. Se debe aceptar que los pacientes deben conocer toda la información necesaria para prestar su consentimiento y para hacer su propia elección de tratamiento, a pesar de las propias inclinaciones personales. La información proporcionada debería incluir los riesgos conocidos y los beneficios esperables, el coste, las posibles complicaciones, las alternativas de tratamiento disponibles y sus costes respectivos, así como la identificación del personal médico que participará directamente en el cuidado del paciente. Hasta donde sea factible deberiamos respetar las opiniones de los pacientes y limitarnos a lo expresado en el propio consentimiento del paciente.

\section{Motivaciones para la búsqueda de actitudes éticas}

Quizás podría bastar con este muestrario de afirmaciones para ser consciente del elevado nivel ético que exige el ejercicio de una profesión sobre la que la sociedad vuelca una gran confianza, aunque no siempre encontremos la reciprocidad esperada a nuestra dedicación profesional o choquemos con la desconfianza de personas que vuelcan sobre nosotros sus pasadas malas experiencias con otros profesionales. Sin embargo, no deberíamos dejarnos llevar por la mediocridad o el desánimo rebajando las exigencias éticas con las que, quizás, iniciamos nuestra andadura profesional. Sin embargo, este riesgo es real. Por ello, parece del todo necesario propiciar foros de debate dentro de la Urología donde se recuerden responsabilidades, se refuercen lazos de compromisos compartidos colectivamente, se expongan dudas y conflictos sufridos en el ejercicio de la profesión y se acuerden principios éticos de actuación con respaldo académico o institucional. Un ambicioso proyecto en este sentido podría ser la creación de Guías de buena práctica ética. Dichos ámbitos de intercambio de experiencias y opiniones pueden servir, además para recordar o dar a conocer la legislación vigente sobre aspectos que afectan a nuestro quehacer 
habitual: responsabilidades ante negativas de tratamiento por parte de los testigos de Jehová, demandas como consecuencias de vasectomías, responsabilidades por las listas de espera, derechos y deberes entre profesionales, legislación sobre trasplantes, marco legal ante situaciones de conflicto en pacientes urológicos terminales, etc.

Una vez aclarado que hay muchos temas y muy importantes de los que hablar dentro de un contexto ético-legal en nuestra especialidad, para los que no estén familiarizados con esta disciplina quizás sería conveniente explicar que los principios de fundamentación de la ética médica constituyen un intento de alcanzar una base de consenso de aceptación universal. Se ha objetado que esta aventura intelectual parece imposible ya que el relativismo cultural se muestra como una barrera aparentemente insuperable en una sociedad pluralista y tremendamente diversificada en sus opiniones. Sin embargo, no es el pacto social la meta de la ética. La dignidad y los derechos humanos no pueden depender en su esencia del beneplácito mayoritario de la sociedad ya que, con ese planteamiento ideológico, se podrían considerar aceptables, en vez de lamentables, situaciones pasadas o presentes tales como el desinterés sobre los marginados de la sociedad, las fobias étnicas sobre las minorías o la segregación social de las mujeres en algunas sociedades. De hecho, precisamente en el ámbito de la medicina es evidente que en unos supuestos acuerdos sociales, los más necesitados de protección (niños, enfermos terminales, discapacitados psíquicos, ancianos, etc.) probablemente nunca estarán presentes en una mesa de negociación sobre sus derechos. Un claro ejemplo de esto es la tendencia a prestar más atención a quienes más la demandan, que no siempre son los que más la necesitan.

Por ello, la reflexión ética no busca el aplauso social inmediato aunque sí aspira a lograr el mayor consenso posible respecto a las mejores opiniones posibles. En este sentido, el afán primordial de los expertos en ética consiste en "cargarse de razones" para hacerse entender por el mayor número posible de personas. Esto incluye también a los poderes públicos ya que la ética debe iluminar el Derecho. Por el contrario, un entramado legal contrario a la ética sólo puede dar lugar a leyes injustas.

\section{Pluralismo y relativismo}

Ahora bien, como afirma Ayllon ${ }^{4}$, la función radicalmente humanizadora de la ética sólo es posible cuando se le reconoce un contenido objetivo, no subjetivo y arbitrario. Si tal pretensión parece razonable, también parece que choca contra el pluralismo y el relativismo de nuestra sociedad. ¿Es inevitable ese choque? ¿Se trata de una contradicción insalvable? La respuesta es diferente para cada caso, pues, aunque pluralismo y relativismo conviven como hermanos gemelos, las apariencias engañan. Analicemos ambos conceptos: El pluralismo supone el reconocimiento práctico de la libertad humana, y consagra la convivencia de conductas diferentes. Sin embargo, sólo es posible cuando las diferencias se apoyan sobre valores comunes. Eso significa que el pluralismo debe afectar a las formas, no al fondo. Porque el fondo en el que se apoya la libertad debe ser un fondo común, que hace las veces de fondo de garantías: las exigencias fundamentales de la naturaleza humana. El pluralismo -a modo de ejemplo- puede admitir diferentes formas de manifestar respeto ante un enfermo terminal o ante un discapacitado psíquico, pero nunca dará por buena la opinión de que estas personas no merecen respeto. El relativismo, en cambio, atenta contra la ética porque pretende poner en el mismo plano todos los argumentos considerándolos como simples opiniones de igual valor. Abre así la puerta del "todo vale”, por donde siempre podrá entrar lo más descabellado, lo irracional. Con esa lógica de papel, el drogadicto al que se le pregunta “¿por qué te drogas?” siempre puede responder “¿y por qué no?”. Entendido como concepción subjetivista del bien, el relativismo hace imposible la ética.

Si la ética fuera subjetiva, el narcotraficante, el pederasta y el homicida podrían afirmar que están actuando éticamente simplemente apelando a su conciencia subjetiva. Es decir, todas las acciones podrían ser buenas acciones. Sin embargo, al igual que el pluralismo, la ética es relativa en las formas, pero no debe serlo respecto al fondo. Como ejemplo clásico, se suele mencionar que de la naturaleza de un recién nacido se deriva la obligación que tienen sus padres de alimentarlo y vestirlo. Son libres para escoger entre diferentes alimentos y vestidos, pero la obli- 
gación es intocable. Subjetivamente pueden decidir no cumplir su obligación, pero entonces estarían actuando objetivamente mal.

Por otra parte, hay una experiencia cotidiana a favor de la objetividad moral. Es la siguiente: la inmoralidad que se denuncia en los medios de comunicación y se condena en los tribunales, no sería denunciable ni condenable si tuviera carácter subjetivo, pues subjetivamente es deseada y aprobada por el que la comete. Con otras palabras: si los juicios morales sólo fueran opiniones subjetivas, todas las leyes que condenan lo inmoral serían simplemente ejercicios de poder de unos frente a otros. En consecuencia, si la moralidad no se apoya en verdades, las leyes se convierten en mandatos arbitrarios del más fuerte: del que tiene poder para promulgarlas y hacerlas cumplir, por las buenas o por las malas.

Así pues, aceptar principios incondicionales por encima de cualquier procedimiento no es consecuencia de una postura acrítica y subjetiva. Es, por el contrario, consecuencia de una reflexión imparcial sobre nuestras intuiciones morales elementales. La responsabilidad materna, antes mencionada, no se funda en una predisposición sentimental, ni en un principio teórico, sino en una percepción básica: dado que el niño necesita de la madre, la madre se debe a él, sin otros razonamientos ni necesidad de consensos.

Por tanto, aceptar normas básicas de conducta moral quiere decir, entre otras cosas, que el debate no es el último fundamento de la ética, pues un fundamento discutible dejaría de ser fundamento. Por eso dice Aristóteles que "quien discute si se puede matar a la propia madre no merece argumentos sino azotes"5. La ética sólo se puede fundamentar sólidamente sobre principios no discutibles aunque esto no exime a nadie del deber de argumentar las propias convicciones intentando buscar el mayor consenso posible para hacerse entender. Pero la referencia a los valores morales como fundamento previo del debate y de la conducta se encuentra hoy bajo sospecha. La objeción más frecuente estima que apelar a una supuesta evidencia de los valores hace imposible un debate racional, pues la evidencia moral debería ser considerada como algo de carácter subjetivo. Esta objeción olvida -entre otras cosas- el reconocimiento universal, por evi- dencia objetiva, de los valores recogidos en la Declaración Universal de Derechos Humanos, de 1948.

Lo anteriormente mencionado puede parecer una compleja disgresión filosófica pero se sitúa en la base de los fundamentos de la Filosofia de la Medicina, que considera como ineludibles los deberes del médico hacia sus pacientes. Enlazando estas argumentaciones con el ámbito de la Urología, llegaremos fácilmente a la conclusión de que todos compartimos obligaciones éticas básicas, tales como el deber de dar información veraz a nuestros pacientes, transmitir también verazmente los datos de nuestras investigaciones y trabajos científicos, manteniendo nuestra independencia ante presiones exteriores, asumir nuestra responsabilidad en la gestión y el uso racional de recursos, mantener una actitud de colaboración sincera entre los miembros del mismo equipo de trabajo o facilitar una atención personalizada y de calidad humana a los enfermos, lo que en definitiva marcará el punto de referencia de nuestro nivel ético individual. Por tanto, como vemos, de una posible reflexión ética colectiva, se podrán deducir normas de comportamiento para el profesional individual, para el trabajo en equipo y para el marco de las instituciones sanitarias. Asumir conscientemente estas obligaciones y ponerlas en práctica contribuirá indudablemente a dignificar nuestra profesión y, en definitiva, a dignificarnos a nosotros mismos.

\section{REFERENCIAS}

1. Torralba F. Filosofia de la Medicina en torno a la obra de E.D. Pellegrino. Madrid; Fundación Mapfre Medicina, 2001.

2. Wilkie P. Ethical issues in urology: the patient's perspective. Br J Urol. 1995; 76(Suppl 2):5-7.

3. American Urological Association Code of Ethics. AUA News. May/June 1999;30.

4. Ayllon JR. Bioética, pluralismo y relativismo. Cuad Bioet. 2003;14(2):209-216.

5. Aristóteles. Ética. Madrid; Ed. LIBSA. Col. Grandes pensadores, 2001.

Dr. J. Jara Rascón

E-mail: jjara@terra.es

(Trabajo recibido el 25 de septiembre de 2006) 